\title{
"UNI DUNI TÊ [...] O ESCOLHIDO FOI VOCÊ": ASPECTOS JURÍDICOS E PSICOLÓGICOS DA SÍNDROME DA ALIENAÇÃO PARENTAL
}

\author{
Hildemar Meneguzzi de Carvalho' \\ Fernanda Carolina de França Barbosa Camara
}

Resumo: Este artigo é resultado da breve análise sobre os aspectos jurídicos e psicológicos da Síndrome da Alienação Parental: fenômeno familiar em que são realizadas campanhas de desqualificação dos genitores perante os filhos, visando o distanciamento entre eles. O assunto ganhou destaque após a promulgação da Lei 12.318, de 26 de agosto de 2010, que regulamentou a prática da alienação parental e delimitou as suas consequências/ sanções, que não possuem natureza punitiva, mas educativa e protetiva. O tema é relevante diante dos efeitos da alienação parental na vida dos envolvidos. Vislumbra-se a necessidade de uma atuação multidisciplinar nos casos onde a alienação parental é identificada, para que as medidas previstas em Lei sejam aplicadas corretamente e resguardem o direito à convivência familiar dos filhos.

1 Juíza de Direito em Santa Catarina, atualmente titular da $2^{\mathrm{a}}$ Vara de Família da Comarca de Joinville e Presidente da $5^{\text {a }}$ Turma de Recursos. Graduada em Direito pela Universidade Federal de Santa Catarina - UFSC e em Psicologia pela Faculdade Guilherme Guimbala - ACE. Especializada em Direito Processual Civil Contemporâneo pela PUC/PR. Mestranda em Ciências Jurídicas pela Universidade do Vale do Itajaí - UNIVALI. E-mail: hmc3772@tjsc.jus.br

2 Residente Judicial no Tribunal de Justiça de Santa Catarina, junto ao gabinete da $2^{\mathrm{a}}$ Vara de Família da Comarca de Joinville e $5^{\mathrm{a}}$ Turma de Recursos, sob a orientação da Juíza de Direito Hildemar Meneguzzi de Carvalho. Bacharel em Direito, graduada pela Universidade da Região de Joinville - UNIVILLE. Cursando o Módulo I (especialização em Direito Público) e o Módulo III (Residência Judicial) da Escola Superior da Magistratura do Estado de Santa Catarina - ESMESC. E-mail: fernandacfbc@gmail.com 
Palavras-chave: Alienação parental. Síndrome da alienação Parental. Lei 12.318/2010. Direito de família. Psicologia.

\section{INTRODUÇÃO}

Trata-se de um fenômeno que atinge famílias por todo o mundo: Alienação Parental e a consequente Síndrome da Alienação Parental (referidas doravante como AP e SAP, respectivamente), que surgem pela intenção de limitar ou cessar o convívio familiar dos filhos com um dos genitores. Justamente, o título do artigo "Uni duni te [...] o escolhido foi você" ${ }^{3}$ remete a uma das principais características da SAP, ou seja, obrigar os filhos a escolherem um dos genitores para amar e respeitar: "Ocorre um constrangimento para que seja escolhido um dos genitores, [...], favorecendo um prejuízo na formação de seu caráter" (VELLY, 2010).

Os primeiros estudos a respeito da SAP foram publicados por volta de 1985, pelo psiquiatra infantil Richard Gardner, o qual conceituou a síndrome como "uma desordem que surge, sobretudo, no contexto das disputas pela custódia das crianças" (GARDNER apud RIBEIRO, 2009). Isso significa que o fenômeno costuma ocorrer num cenário de animosidade entre os genitores, após a ruptura conjugal. Contudo, não se exclui a possibilidade da alienação iniciar-se na constância da união, com os genitores residindo na mesma casa, ou através de terceiros; como os familiares que tomam as dores de um dos genitores e contribuem, direta ou indiretamente, na campanha de desqualificação.

O primeiro tópico tratará do instituto da família: da sua evolução histórica e do exercício do poder familiar em substituição ao pátrio poder. O segundo tópico abordará concisamente as rupturas conjugais. Por fim, o terceiro tópico versará exclusivamente sobre a AP e SAP: do seu histórico e conceito,

3 Trecho de música infantil da cantora 'Sandra', disponível em: <http://letras.mus.br/ cantora-sandra/1640406/>. Acesso em: 28 ago. 2014. 
das suas principais características e consequências, e da Lei 12.318/2010.

O objetivo geral do presente texto consiste na análise psicojurídica da AP e da SAP. Já os objetivos específicos estão diretamente relacionados à análise dos prejuízos que a prática da AP e o desenvolvimento da SAP causam aos filhos alienados, observando-se que, com a evolução do Direito de Família, crianças e adolescentes tornaram-se sujeitos de direitos, protegidos por uma série de leis, tais quais: Constituição Federal de 1988, Estatuto da Criança e do Adolescente, Código Civil de 2002 e a mais recente Lei 12.318/2010, que versa exclusivamente sobre a AP.

\section{INSTITUIÇÃO DA FAMÍLIA E PODER FAMILIAR}

Neste primeiro momento, para captar a AP e a SAP, é necessário tecer breves comentários sobre a família e o exercício do poder familiar.

\subsection{A instituição da família}

O estudo da doutrina conduz a diversos conceitos de família, destacando-se a sua importância para o indivíduo integrante de uma sociedade. Do ponto de vista sistêmico, a família "é um grupo de pessoas interdependentes, inter relacionadas. [...] São as primeiras pessoas que se envolvem efetivamente e afetivamente formando uma rede de proteção, espaço de inclusão, de pertencimento" (MATOS, 1999. p. 37).

Noronha e Parron (2012) afirmam que: "[...] o grande vínculo natural que une o homem à família faz tornar verdadeira a máxima de que não existe qualquer outra instituição que seja tão intimamente ligada a ele". Eis o motivo pelo qual afirma-se que "a família está implicada no desenvolvimento saudável, ou não, de seus membros, já que ela é entendida como sendo o elo que os une às diversas esferas da sociedade" (SCHENKER e MINAYO, 2004). 
Com efeito, Oliveira, Bittencourt e Carmo (2008) ressaltam a importância da família como instituição cuidadora de seus membros e responsável pela transmissão de valores éticos e morais, sendo na unidade familiar, "espaço de convivência e de experiências; sejam elas de fracasso ou sucesso, saúde ou doença, que se encontra a proteção para os filhos contra os fatores de risco", como o envolvimento com drogas, por exemplo.

Para compreender a prática da AP dentro da família contemporânea, é forçoso discorrer, ainda que brevemente, sobre a evolução histórica dessa instituição.

\subsubsection{Transformação histórica da família}

Dias (2010, p. 27) defende que a função de cada componente da família é previamente estabelecida por conceitos culturais e temporais, de forma que o instituto familiar dispõe de estruturação psíquica na qual todos ocupam um lugar e possuem uma função: "lugar do pai, lugar da mãe, lugar dos filhos, sem, entretanto, estarem necessariamente ligados biologicamente". No mesmo sentido, Silva (2011, p. 62) assevera que "a família sempre foi e é considerada a célula mater da sociedade, porém, dependendo da perspectiva com que é vista, modificam-se os paradigmas e características da sua constituição”. Isto quer dizer que cada período da história apresentou estruturas familiares diferentes, condizentes com a cultura da época.

A começar pelo período romano, em que a família vivia sob o comando autoritário do marido, que exercia o pater familias tanto em relação à vida de seus filhos, quanto em relação à vida de sua esposa, sendo esta subordinada a ele. Na família patriarcal "o homem apoderou-se da direção da casa, convertendo a mulher em sua escrava e simples objeto de reprodução" (CENTA e ELSEN, 2006). O pátrio poder concedia ao genitor o poder absoluto em relação aos filhos, os quais não eram considerados sujeitos de direito, mas propriedades, salientando-se que "era atribuição do pai deter a guarda exclusiva 
dos filhos, enquanto a mãe se submetia às suas determinações" (BARRETO, 2003).

Há reconhecimento pela doutrina jurídica de que o Direito Romano forneceu ao Direito Brasileiro elementos básicos da estruturação da família "como unidade jurídica, econômica e religiosa, fundada na autoridade de um chefe" (NOGUEIRA, 2012).

Em seguida contemplou-se o período canônico, em que a família surgia e era representada pelo sacramento, ou seja, pelo casamento e dogma cristão. Oliveira (2005) comenta que "a Igreja Católica conseguiu impor, por intermédio do Direito Canônico [...], a tese da indissolubilidade do casamento", sendo a realidade da época representada pela parábola cristã: "Não separe o homem o que Deus uniu" (CAHALI, 2000).

Neste período mãe e pai eram incentivados a exercerem seus papéis, sendo que em cada cobrança de uma função ou de um comportamento específico, estava implícita uma vantagem futura ou uma ameaça à aceitação social de determinada família (REIS, 2009, p. 41). A figura do chefe da família ainda era tão visível quanto no período romano, prevendo o Código Civil a "superioridade absoluta do marido e do pai na família, o qual dominava o espaço público e o privado: era ele o senhor do dinheiro e do poder de decisão; dava o nome à prole" (CENTA e ELSEN, 2006).

Como consequência da ausência masculina a partir da Primeira Guerra Mundial, a mulher passou a assumir o projeto individualizante da modernidade (BRAGA e AMAZONAS, 2005). Dias (2010, p. 28) confirma:

Esse quadro não resistiu à revolução industrial, que fez aumentar a necessidade de mão-de-obra [...]. Foi assim que a mulher ingressou no mercado de trabalho, deixando o homem de ser a única fonte de subsistência da família, que se tornou nuclear, restrita ao casal e a sua prole. 
Posteriormente, no período das codificações, surgiu a ideia de um corpo de leis ordenado e sistematizado, sendo o direito civil identificado. O Código Civil de 1916 foi um marco histórico em relação ao Direito de Família, na medida em que o pátrio poder passou a ser flexibilizado pelo ordenamento. No entanto, o referido período ainda carregava consigo os valores familiares conservadores, pois continuava sendo inviável a dissolução do casamento e devida a diferenciação dos filhos, entre os biológicos e adotivos, legítimos ou não.

A grande mudança ocorreu apenas com o advento do Código Civil de 2002.

Entre os Códigos Civis de 1916 e 2002, além da natural evolução dos costumes que determinaram o fim da indissolubilidade do casamento e a extensão do poder familiar à mulher, existe um marco histórico temporal que é a carta Magna de 1988 quando se estuda o Direito de Família no Brasil. O legislador constituinte visivelmente pretendeu contornar as distinções, preconceitos e desigualdades existentes no Direito familiar brasileiro, assim como, consolidar as conquistas de forma que introduziu o conceito de união estável, reduziu de cinco para dois anos o tempo exigido para o divórcio direto e impediu qualquer discriminação a respeito da origem dos filhos entre outros temas reservados à legislação ordinária agora, tratados pela Constituição Federal. (NOGUEIRA, 2012)

O Código Civil de 2002 permitiu que o Direito de Família tomasse um rumo diferente daquele trilhado pelo período romano e canônico, pois veio reconhecer a necessidade de adaptar o direito à realidade das famílias brasileiras.

\subsection{Poder familiar}

O Pátrio Poder rotulava a mulher como "[...] vítima inerme do domínio ou do abuso do homem" (FREYRE, 2003, p. 57), sendo ela "criatura reprimida sexual e socialmente dentro da 
sombra do pai ou do marido" (FREYRE, 2003, p. 57), não possuindo direitos em relação aos filhos, tampouco voz para auxiliar o pai na educação dos mesmos.

A evolução histórica do Direito de Família ${ }^{4}$ deu ensejo à substituição do Pátrio Poder pelo Poder Familiar, sendo conferido aos pais, destarte, em igualdade de condições e independentemente do sexo, a responsabilidade pelo "[...] cumprimento de todas as atribuições que lhes são inerentes” (COMEL, 2004).

O tratamento isonômico entre o homem e a mulher foi reconhecido juridicamente apenas com a promulgação da Constituição Federal de 1988; de forma geral no art. 5: "Todos são iguais perante a lei, [...]. I - homens e mulheres são iguais em direitos e obrigações, nos termos desta Constituição;", e de forma específica no art. 226, § 50: "Os direitos e deveres referentes à sociedade conjugal são exercidos igualmente pelo homem e pela mulher".

A expressão Poder Familiar foi ideia proposta por Miguel Reale ao Senado Federal, nos termos da Resolução 01/2000, com a justificativa de que a expressão Pátrio Poder era "[...]denotadora da prevalência do cônjuge varão sobre a pessoa dos filhos", reconhecendo-se, então a necessidade de substituição para que dúvida não houvesse sobre a posição da mulher na direção da sociedade conjugal, exercida por ambos, em colaboração, sempre no interesse do casal e dos filhos. (MUSSELI, 2011).

E foi somente no ano de 2009 que o Estatuto da Criança e do Adolescente, acompanhando a evolução das relações familiares, modificou a expressão 'Pátrio Poder' por 'Poder Familiar': "Art. 21. O poder familiar será exercido, em igualdade de condições, pelo pai e pela mãe, [...].”.

No Código Civil de 2002, o art. 1.630 prevê que "Os filhos estão sujeitos ao poder familiar, enquanto menores" e

4 Ver tópico 2.2. 
o art. 1.634 da mesma Lei elenca algumas das atribuições dos genitores no exercício do poder familiar:

Art. 1.634. Compete aos pais, quanto à pessoa dos filhos menores: I - dirigir-lhes a criação e educação; II - tê-los em sua companhia e guarda; III - conceder-lhes ou negar-lhes consentimento para casarem; IV - nomear-lhes tutor por testamento ou documento autêntico, se o outro dos pais não lhe sobreviver, ou o sobrevivo não puder exercer o poder familiar; V - representá-los, até aos dezesseis anos, nos atos da vida civil, e assisti-los, após essa idade, nos atos em que forem partes, suprindo-lhes o consentimento; VI - reclamá-los de quem ilegalmente os detenha; VII - exigir que lhes prestem obediência, respeito e os serviços próprios de sua idade e condição.

O poder familiar pode ser associado a um encargo, atribuído pelo Estado aos genitores, "no intuito de que estes zelem pelo futuro de seus filhos, que serão posteriormente entregues à sociedade" (DILL e CALDERAN, 2010). O mesmo encargo, também confere aos filhos obrigações, como obediência aos genitores, à luz do art. 1.634, inciso VII, do Código Civil (mencionado acima), salientando-se que a autoridade do pai deverá sempre ser exercida dentro dos limites da lei, em benefício ao desenvolvimento dos filhos (DILL e CALDERAN, 2010).

O poder familiar é irrenunciável, intransferível, inalienável, imprescritível [...]. As obrigações que dele fluem são personalíssimas. Como os pais não podem renunciar aos filhos, os encargos que derivam da paternidade também não podem ser transferidos ou alienados. Nula é a renúncia ao poder familiar, [...]. (DIAS, 2010. p. 414)

Importante registrar que as obrigações estabelecidas pelo Poder Familiar não dizem respeito somente ao campo material, mas também ao campo existencial/emocional, à medida que os pais precisam dispensar afeto e atenção aos filhos (DIAS, 2010, 
p. 414). O Poder Familiar assumiu como prioridade, portanto, a proteção das crianças e adolescentes, "com mais características de deveres e obrigações dos pais para com os filhos do que de direitos em relação a eles" (DIAS, 2010. p. 413).

Nesse contexto os filhos tornaram-se sujeitos de direito, inseridos em uma sociedade cada vez mais preocupada com sua integridade física e emocional, que passou a entender a família como "o lugar típico onde os complexos se formam e adquirem estabilidade, [...] organizando o desenvolvimento psíquico" (GARCIA, 2004, p. 28). No mesmo sentido, Freud, muito antes, já havia afirmado que "a criança é o pai do homem". E Dias (2010, p. 414), complementando o pensamento, asseverou que a autoridade parental acaba conduzindo os filhos à "autonomia responsável".

Pelas razões até então expostas, foi adotada pelo ordenamento jurídico brasileiro a doutrina da proteção integral de crianças e adolescentes, de maneira que "quando ocorrem conflitos, como, por exemplo, no caso da dissolução de um casamento, os interesses da criança sobrepõem-se aos de outras pessoas ou instituições” (CIRINO, 2001, p. 36), conforme se discorrerá no tópico a seguir.

\section{RUPTURAS CONJUGAIS}

Diferentemente da família patriarcal, a família contemporânea pode dissolver-se facilmente no âmbito jurídico. No entanto, a discussão em torno da dissolução de uma estrutura familiar não é apenas jurídica: "[...] a matéria é, antes, do domínio da sociologia, pois transcende os limites do direito e interessa à moral, aos costumes e à educação" (CAHALI, 2000, p. 23). Isto porque, apesar do crescente número de rupturas conjugais, os membros de uma família, em geral, não estão preparados para o impacto emocional, social e econômico que a situação acarreta (CANO; GABARRA e MORÉ, 2008). 
A separação do casal não acaba com a família, porém a transforma. Em outras palavras, a estrutura se altera com a dissolução da conjugalidade, embora a família, enquanto organização, se mantenha. (CANO e GABARRA, 2008)

Ou seja, ainda que o casal decida pelo fim no relacionamento, deve estar ciente de que o poder familiar permanecerá existindo, sofrendo o seu exercício apenas algumas adaptações, ou, para Cahali (2000, p. 19) "abrandamentos": "A unidade da família não se confunde com a convivência do casal, é um elo que se perpetua independentemente da relação dos genitores" (DIAS, 2010, p. 416).

Quando os cônjuges decidem pela dissolução da relação e essa ocorre em meio a traições, agressões e desentendimentos em geral, costumam ter dificuldades para colocarem suas mágoas e dores de lado e prestarem atenção nos filhos, que sofrem imensamente com a situação: "em verdade, o problema está nos adultos conflitantes, que devem se despojar de seus egos para conseguirem enxergar um outro ser, além do umbigo: o próprio filho” (NUNEZ, 2013). É durante a ruptura conjugal que os filhos mais precisam dos genitores, principalmente quando decidem litigar judicialmente pela sua guarda, disputa que geralmente é marcada por tensões e hostilidades. Os genitores, em nome dos direitos que acreditam possuir, chegam a transformar o litígio em uma competição, onde, para mostrar ser o melhor, é válido até a expressa depreciação do outro: "[...] faz-se guerra para ganhar, e não porque ela é justa” (REIS, 2009, p. 103).

Nessa medida, a metáfora da guerra, muito usada no espaço jurídico, tem uma aplicação interessante nas Varas de Família, onde as duas partes são incitadas a reunir todo um 'exército' para participar da batalha. Avós, amigos, irmãos, vizinhos, professores médicos psicólogos, enfim, uma série de 'recrutas', não raro, vêm testemunhar em favor de um lado ou de outro, tanto para falar a respeito das questões mais triviais da rotina de uma família - 
que somente depois da separação passaram a constituir problema -, como também para embasar as acusações que precisam estar ancoradas na fala de especialistas. (REIS, 2009, p. 115)

Este cenário dá ensejo ao tema do presente artigo: AP e SAP.

\section{ALIENAÇÃO PARENTAL: DA CONDUTA À SÍNDROME}

Primeiramente, é forçoso identificar a origem da AP e da SAP, que constituem institutos distintos, derivando o segundo do primeiro.

A prática da AP não é recente, mas sim "utilizada de forma recorrente e irresponsável desde sempre” (DIAS, 2010, p. 451), principalmente na família patriarcal, em que o marido/ genitor possuía todo o poder sobre a família. Entretanto, com a evolução do Direito de Família e com a transformação das crianças e adolescentes em sujeitos de direitos ${ }^{5}$, o assunto passou a receber devida atenção e específica denominação. A AP, como Síndrome (SAP), foi identificada em 1985 pelo professor de Psiquiatria Infantil da Universidade de Columbia (EUA), Dr. Richard Gardner, sendo difundida posteriormente com as contribuições de François Podevyn, a partir de 2001, e outros profissionais norte-americanos que trabalhavam com crianças e famílias no contexto pós-divórcio (DIAS, 2010, p. 22 e 41).

Para Dias (2010, p. 16), a AP funda-se nos atos praticados pelo 'alienante', enquanto a SAP consiste nos sintomas instalados pela conduta. Em síntese, a AP transforma-se em SAP quando atinge sua finalidade, isto é, quando limita ou cessa o contato dos filhos com o genitor alienado.

\subsection{Conceito}

Quando o vínculo conjugal se desfaz, é necessária uma reestruturação familiar. Os genitores precisam diferenciar o

5 Ver tópico 2.3. 
papel de companheiros/cônjuges do papel parental (DIAS, 2010, p. 37). No entanto, no cenário de uma separação de fato, não raros são os sentimentos negativos de raiva, decepção, abandono, rejeição, traição e etc., que, se não assimilados, podem ocasionar um desejo de vingança e dar início a um "jogo de manipulações" (DIAS, 2010, p. 452). Devido a esses sentimentos aflorados, não há flexibilidade, nem interesse no gerenciamento dos conflitos para dar aos filhos exemplos de diálogo, negociação e entendimento (GOETZ e VIEIRA, 2009, p. 82). Pelo contrário, para a concretização desta 'justiça emocional' utilizam-se os filhos, originando-se, então, a AP.

Para Vieira Segundo (2009), a SAP representa uma das várias formas de Bullying, implicando em "agressões repetidas sem qualquer justificativa, que visam colocar a vítima em constante estado de tensão”.

Os filhos tornam-se instrumentos de vingança, sendo impedidos de conviver com quem se afastou do lar. São levados a rejeitar e a odiar quem provocou tanta dor e sofrimento. Ou seja, são programados para odiar. Com a dissolução da união, os filhos ficam fragilizados, com sentimento de orfandade psicológica. Este é um terreno fértil para plantar a ideia de abandonada pelo genitor. Acaba o guardião convencendo o filho de que o outro não lhe ama. Faz com que acredite em fatos que não ocorreram com o só intuído de levá-lo a afastar-se do pai. (DIAS, 2010, p. 15)

Por este motivo, a SAP é igualmente denominada de "Síndrome dos Órfãos de Pais Vivos" (DIAS, 2010, p. 41) ou "Síndrome da Implantação de Falsas Memórias" (DIAS, 2010, p. 451), onde ocorre a identificação dos filhos alienados com o genitor patológico, "passando a aceitar como verdadeiro tudo que lhe é informado" (VIEIRA, 2013, p. 93).

Por ferir o direito dos filhos à plena convivência familiar e causar-lhes sentimento de medo, insegurança e culpa, a SAP é tratada como abuso psicológico, "[...] sutil, [...] difícil de 
mensurar objetivamente -, mas que poderá trazer sérias consequências psicológicas e provocar problemas psiquiátricos pelo resto da vida" (SILVA, 2011, p. 209). Gardner (2002), inclusive, defende que a SAP pode se apresentar como um abuso mais grave e traumático do que abusos físicos ou sexuais, "porque pode razoavelmente conduzir ao enfraquecimento progressivo da ligação psicológica entre a criança e um genitor amoroso" (GARDNER, 2002), ligação esta essencial ao seu desenvolvimento.

Por compor-se de características tão subjetivas, a identificação da SAP demanda cautela e atuação de profissionais competentes, consagrando-se a interdisciplinaridade do Direito de Família com a Psicologia Jurídica. À vista disso, havendo indícios da prática de AP, é indispensável a prévia atuação de psicólogos, psiquiatras e assistentes sociais, que possuem conhecimento para analisar o caso específico, identificando a realidade por detrás das alegações feitas no ingresso do processo judicial, os atores (alienante e alienados), as formas como a AP está sendo desenvolvida e o nível em que se encontra (TOLOI, 2010, p. 107). Tal investigação visa dar subsídios ao magistrado, para que o mesmo profira sua decisão com segurança, de estar priorizando e resguardando o melhor interesse dos filhos alienados.

\subsection{Consequências psicológicas da SAP}

Como qualquer abuso, a SAP possui severas consequências para os filhos alienados. Trata-se, em verdade, de comportamento que, se não identificado e trabalhado no início, tende a instaurar vínculos patológicos e vivências contraditórias, instaurando "um olhar destruidor e maligno sobre as relações amorosas em geral" (DIAS, 2010, p. 24). Goudard (2008) afirma que as consequências registradas tratam de distúrbios psicopatológicos, psicossomáticos e até físicos; o autor ainda defende que o mais importante é fazer um diagnóstico precoce, porque 
quanto mais cedo o distúrbio for encontrado, maior será a margem de prevenção e de diálogo.

Obviamente os efeitos da SAP oscilam de pessoa para pessoa, considerando a complexidade humana e cuidando de fatores que podem estar explícitos, mas também recônditos: "variam de acordo com a idade da criança, com as características de sua personalidade, com o tipo de vínculo anteriormente estabelecido, e com sua capacidade de resiliência" (DIAS, 2010, p. 25).

É meritório apontar que os distúrbios decorrentes da SAP podem ser transgeracionais, porque representam um mecanismo de adaptação familiar que se reproduz (GOUDARD, 2008), ou seja, a conduta, assim como as sequelas, podem perpetuar por diversas gerações, nem sempre sendo possível a sua reversão. Fonseca (2006), aliás, comenta que para os filhos alienados, a superação da SAP pode exigir um trabalho de anos, podendo ocorrer apenas com o rompimento da relação com genitor alienante, "o que lhe permite entrever a irrazoabilidade do distanciamento a que foi induzido".

De fato, com os estudos desenvolvidos sobre o tema, já é possível traçar um perfil do genitor ou terceiro alienante e filho alienado, apontando-se as consequências 'genéricas' da SAP, tanto físicas quanto emocionais.

Cabe mencionar aqui a expressão 'luto impossível', abordada por Goudard (2008) de forma bastante impactante, ante a impossibilidade de qualquer relação entre filhos e genitor alienado, como se um deles fosse falecido: "A esperança de revê-lo existe, portanto iniciar um trabalho de luto nessas condições é impossível”. E diante dessa situação indefinida e dos sentimentos simultâneos de esperança e de orfandade viva, não causam surpresas as consequências negativas da SAP para os filhos (GOUDARD, 2008), sendo a síndrome graduada em estágios, a saber: leve, moderado e grave (VERSIANI, 2009).

Gardner (2002) observou que crianças e adolescentes alienados comumente são diagnosticados com transtorno de 
conduta: "Um padrão de comportamento repetitivo e persistente no qual os direitos básicos dos outros, assim como normas/ regras sociais importantes, adequadas à idade, são violados". Dias (2010), sobre isso, atestou que o conjunto de sintomas da SAP é expresso em termos de enfermidade somática e comportamental:

[...] sob forma de ansiedade, medo e insegurança, isolamento, tristeza e depressão, comportamento hostil, falta de organização, dificuldades escolares, baixa tolerância à frustração, irritabilidade, enurese, transtorno de identidade ou de imagem, sentimento de desespero, culpa, dupla personalidade, inclinação ao álcool e às drogas, e, em casos mais extremos, ideias ou comportamentos suicidas. (DIAS, 2010, p. 25)

A SAP também costuma causar o conhecido 'efeito bumerangue': quando, no início da adolescência, o filho que sofreu alienação se dá conta de que o genitor alienado foi submetido a uma injustiça, momento em que é acometido por intenso sentimento de culpa e geralmente volta-se contra o genitor alienante (VELLY, 2010). Neste contexto fica claro que uma das características mais cruéis da SAP é a obrigatoriedade dos filhos escolherem a um dos genitores para dispensar seu amor, respeito e lealdade: "O genitor alienante subentende que somente pode ser um OU outro, de maneira exclusiva. [...]. Este genitor é frequentemente aquele de quem elas mais têm medo de ser rejeitadas" (GOUDARD, 2008).

No âmbito escolar, Silva (2011, p. 210) defende que os filhos alienados desenvolvem mecanismos de defesa psíquica, como a racionalização (sempre encontram uma explicação lógica para tudo); e a sublimação (quando utilizam os estudos ou recursos socialmente aceitáveis para não lidar com o 'caos' familiar, como as discórdias e brigas entre os pais).

Mas a vitimização do filho alienado não é absoluta, pois a SAP pode ensiná-lo a arte da manipulação, tornando-o "prema- 
turamente esperto [...], para falar apenas uma parte da verdade e, por fim, para enredar-se em mentiras [...] e exprimir emoções falsas" (SILVA, 2011, p. 209/210). A longo prazo, sobreleva-se a possibilidade do alienado enfrentar dificuldades para assumir relações estáveis na fase adulta, e, ainda, "problemas quanto à sexualidade, falta de sensibilidade moral, falta de remorso e etc." (VIEIRA, 2013, p. 95). Portanto, evidente que a SAP influencia na personalidade de indivíduos que farão parte da sociedade, contrairão relações e obrigações, e construirão, muito provavelmente, suas próprias famílias, mas fortemente tendenciosos a reprisarem a alienação.

Da SAP surgem sentimentos de tanta impotência, carência e abandono, que Silva (2011, p. 213) atesta a conduta como "a mais pura maldade", tal qual toda espécie de abuso contra crianças e adolescentes.

Lavagem cerebral, programação, manipulação, qualquer termo com o qual queira chamar esse processo, é destrutivo para a criança e para o genitor alienado. Nenhum dos dois será capaz de levar uma vida normal e saudável a menos que o dano seja interrompido. (DARNALL, 2011, p. 213)

Conquanto as consequências exibidas acima sejam graves, a SAP não é uma situação irreversível, desde que ocorram intervenções, em tempo, de medidas legais e terapêuticas. Novamente, salienta-se que nem todo o exposto aplica-se aos alienados. Quer-se apenas demonstrar que a SAP possui consideráveis consequências, que podem - ou não - recair sobre os filhos, devendo cada caso ser compreendido na sua particularidade.

\subsubsection{Memórias inventadas}

Como o próprio nome sugere, as falsas memórias são criadas a partir da manipulação da memória. A vítima interioriza fatos que não ocorreram, como, por exemplo, no caso de crianças que afirmam terem sido vítimas de abuso sexual, desco- 
brindo-se, posteriormente, que tratou-se de episódio implantado. Essas influências costumam ser absorvidas com maior facilidade por crianças, que acabam 'atuando' nesses 'cenários inventados' (SILVA, 2011, p. 217). Dias (2010, p. 17) sustenta que "a criança nem sempre consegue discernir que está sendo manipulada e acredita naquilo que lhe é dito de forma insistente e repetida".

A alienação, primeiro do consciente e depois do inconsciente dos filhos, é uma característica específica da SAP, pois comumente advém dos genitores que, "no auge de seu transtorno, fazem falsas acusações contra o outro genitor, a quem desejam punir ou afastar" (PAULO, 2011). Os filhos realmente confiam no acontecimento que limitou ou rompeu a sua relação com o genitor alienado, razão pela qual o fenômeno também é conhecido pela expressão 'pensador independente' (SILVA, 2011, p. 225), pois interiorizado o fato, a criança ou adolescente alienado contribui automaticamente para a reprodução da mentira, adotando veementemente como suas as palavras e argumentos do alienante.

Uma frase de Velly (2010) sintetiza com maestria o tema: "Existem memórias que eu só conheço de nome. Posso imaginar que as tenho, mas na realidade nunca vivi". Assim, defende-se que a conduta é um desmembramento da AP.

\subsubsection{Falsas denúncias de abuso sexual}

Uma das condutas mais graves da AP são as imputações de falsos abusos sexuais. $\mathrm{O}$ alienante, nesse caso, influencia a criança ou o adolescente de tal modo, que os mesmos passam a acreditar que sofreram abuso sexual por parte do genitor alienado. Essa é, de fato, a mais eficaz das práticas alienadoras: "o processo acabará operando a favor de quem fez a acusação, pois até que se esclareça a verdade, [...], a demora prejudicará quem for inocente" (ROSA, 2008). 
A falsa denúncia é, também, uma forma de abuso, pois as crianças são, compulsoriamente, submetidas a uma mentira, sendo emocional e psicologicamente manipuladas e abusadas. Essa falsa denúncia passa a fazer parte de suas vidas e, por causa disso, terão de enfrentar vários procedimentos (análise social, psiquiátrica e judicial) com o fito de esclarecimento da verdade). (DIAS, 2010, p. 49)

A denúncia de um abuso sexual exige rápida atuação interdisciplinar, preferencialmente com o ramo da Psicologia Cognitiva, que estuda a memória e os processos cognitivos: "No caso das 'lembranças' de agressões ou abusos que não ocorreram, ela permite estabelecer se um testemunho é exato e se pode ser utilizado como prova para o convencimento do juiz" (SILVA, 2011, p. 217). Trata-se de uma investigação complexa, mas alguns doutrinadores já reconhecem pontos que diferenciam testemunhos verdadeiros dos manipulados. Para Paulo (2011), as recordações dos filhos abusados são muito nítidas, bastando uma palavra para ativá-las; enquanto as recordações do alienado necessitam de ajuda para serem 'acessadas'.

A problemática desse tipo de denúncia repousa no 'medo' de negligenciar uma criança e adolescente vítima de abuso. Por isso, como alternativa, alguns magistrados estão determinando a continuidade das visitas, contudo de forma monitorada, geralmente no setor de mediação familiar, "a fim de manter o vínculo tão indispensável ao desenvolvimento saudável e integral da criança [...]" (PAULO, 2011). Tal medida não significa que os tribunais estejam desmerecendo os relatos de abusos sexuais, porque sabem da alta incidência do crime contra crianças e adolescentes. Por outro lado, já foi percebida certa 'banalização' dessas denúncias, que podem resultar em consequências tão nefastas quando às de acusações verdadeiras.

Exige-se, por conseguinte, que os profissionais da área de família atentem-se aos sinais apresentados pelas partes e analisem os casos "além da leitura dos autos" (DIAS, 2010, p. 
55), não negligenciando ora as supostas vítimas, ora as relações parentais.

\subsubsection{Características psicológicas do alienante}

Não se intenta elencar taxativamente as características do sujeito alienante, pois, como dito anteriormente, deve-se considerar a complexidade de cada indivíduo, dentre inúmeros fatores. Contudo, alguns comportamentos são indicados por vários autores como integrados à personalidade de quem aliena.

Dias (2010, p. 25), identifica no sujeito: "Dependência; baixa autoestima; condutas de desrespeito a regras; hábito contumaz de atacar as decisões judiciais; litigância como forma de manter aceso o conflito familiar e de negar a perda;". A autora também fala sobre os sentimentos do alienante: "Os sentimentos do alienador possuem um denominador comum, que, num entendimento psicodinâmico, se organiza pela prevalência dos sentimentos de ódio sobre os sentimentos de amor e gratidão." (DIAS, 2010, p. 29). E esses sentimentos de ódio podem estar intimamente ligados à dificuldade de defrontar a própria derrota, pelo insucesso do relacionamento: "o corpo de amor (a-mors = não à morte) se transforma no corpo de dor (de destruição da vida), gerando uma senda infinita de sofrimento aos filhos e ao cônjuge alienado." (DIAS, 2010, p. 25).

Isto posto, atenta-se que a conduta do alienante pode estar disfarçada com as melhores intenções, e que a tentativa de tipificá-la possui o escopo de facilitar a identificação da SAP e desestruturar os seus mecanismos de funcionamento.

\subsection{Consequências jurídicas da SAP}

A partir do momento em que crianças e adolescentes tornaram-se sujeitos de direitos, iniciou-se uma nova era para o Direito de Família: "Vive-se um momento de privilegiada mudança; legisla-se para a Família do Futuro, não mais será 
preservado o aspecto patrimonialista em detrimento da pessoa" (LAGRASTA, 2012, p. 35). Neste contexto, as leis contemporâneas refletiram uma grande preocupação com a proteção da criança e do adolescente, tratando com absoluta prioridade, por exemplo, o direito deles à convivência familiar (art. 227 da Constituição Federal), o qual, por sua vez, é traumaticamente violado com a prática da AP.

Em verdade, a criança que vivencia o processo de Alienação Parental tem violados e desrespeitados, direta e intencionalmente, os seus direitos [...]. Ela deixa de ser percebida como sujeito de direito para se tornar objeto de satisfação dos desejos do alienador, que a trata como propriedade sua, não restando ao genitor alienado outra alternativa a não ser recorrer ao Judiciário para ver garantido seu lugar na vida do filho. O Judiciário torna-se, então, uma metáfora paterna, colocando limites à atuação do alienador. (PAULO, 2011)

É este o cenário que clamou pela criação de legislação específica, que, com um caráter puramente pedagógico, recriminasse a SAP. Surgiu, então, a Lei 12.318/2010, que em seu art. $2^{\circ}$, parágrafo único, elenca exemplificadamente condutas que podem configurar a prática de AP:

[...] I - realizar campanha de desqualificação da conduta do genitor no exercício da paternidade ou maternidade; II - dificultar o exercício da autoridade parental; III - dificultar contato de criança ou adolescente com genitor; IV - dificultar o exercício do direito regulamentado de convivência familiar; $\mathrm{V}$ - omitir deliberadamente a genitor informações pessoais relevantes sobre a criança ou adolescente, inclusive escolares, médicas e alterações de endereço; VI - apresentar falsa denúncia contra genitor, contra familiares deste ou contra avós, para obstar ou dificultar a convivência deles com a criança ou adolescente; VII - mudar o domicílio para local 
distante, sem justificativa, visando a dificultar a convivência da criança ou adolescente com o outro genitor, com familiares deste ou com avós.

$\mathrm{O}$ art. 30 criminaliza a AP, reafirmando o caráter abusivo da conduta, uma vez que "fere direito fundamental [...] de convivência familiar saudável, prejudica a realização de afeto nas relações com genitor e com o grupo familiar, constitui [...] descumprimento dos deveres inerentes à autoridade parental [...]" (Lei 12.318/2010). Já o art. 4 prevê que o processo versando sobre a SAP terá tramitação prioritária, permitindo-se a tomada, por requerimento ou de ofício, em ação autônoma ou incidental, de medidas provisórias necessárias para preservação da integridade psicológica dos filhos (Lei 12.318/2010). O art. 5 dá autonomia ao juiz para determinar perícia psicológica ou biopsicossocial quando houver indícios da prática da AP (Lei 12.318/2010).

Em seguida, o art. $6^{\circ}$ traz medidas aplicáveis, de forma individual ou cumulada, aos genitores alienantes, se caracterizados atos típicos de AP e para atenuar ou extinguir os seus efeitos. Destaca-se que essas medidas são exemplificativas e não conferem prejuízos à responsabilidade civil ou criminal. São elas:

I - declarar a ocorrência de alienação parental e advertir o alienador; II - ampliar o regime de convivência familiar em favor do genitor alienado; III estipular multa ao alienador; IV - determinar acompanhamento psicológico e/ou biopsicossocial; $\mathrm{V}$ - determinar a alteração da guarda para guarda compartilhada ou sua inversão; VI - determinar a fixação cautelar do domicílio da criança ou adolescente; VII - declarar a suspensão da autoridade parental. (Lei 12.318/2010)

Com relação às sanções, percebe-se a reversão da guarda, em especial, como medida drástica, pois inegável a dificuldade de romper a relação simbiótica do filho alienado com o alienante. Contudo, segundo Gardner (2001), apesar da compre- 
ensível resistência do Judiciário em determinar a reversão da guardam, a medida é, muitas vezes, "a única esperança de salvação para o filho e para o vínculo parento-filial”. Brazil (2010, p. 49) afiança a vestimenta pedagógica da norma, que não visa castigar o genitor, mas distanciar os filhos das condutas alienadoras. Essas medidas repressoras, se previstas, precisam ser aplicadas. Gardner (2009) ressalta a importância das sanções previstas pela Lei serem aplicadas sem dificuldades pelo Poder Judiciário, para preservar a credibilidade do Tribunal, se este realmente se preocupar, acima de tudo, com o bem estar dos filhos alienados.

$\mathrm{O}$ art. $7^{\circ}$ dispõe que a fixação da guarda dar-se-á sempre àquele que viabilizar aos filhos a convivência familiar, possibilitando, consequentemente, o exercício da guarda na modalidade compartilhada (Lei 12.318/2010). Enfim, no que diz respeito ao trâmite processual, o art. $8^{\circ}$ considera a alteração de domicílio dos filhos irrelevante para a determinação da competência relacionada às ações fundadas em direito de convivência familiar, a menos que tenha sido consentida pelo outro genitor ou por decisão judicial (Lei 12.318/2010).

A normatização da SAP veio atender à demanda social por maior equilíbrio nos arranjos familiares, com a participação igualitária dos genitores na formação de seus filhos. Não se espera da Lei, evidentemente, o efeito de um remédio, que leve à mágica transformação de costumes ou eliminação de dificuldades inerentes a processos de AP. Razoável é considerá-la como mais um ingrediente para redefinição de papéis parentais, bem como mais uma ferramenta para assegurar a efetividade na atuação do Poder Judiciário.

\section{CONCLUSÃO}

Embora a AP e a SAP sejam identificadas habitualmente no bojo de um processo judicial, sua origem precede a ele, sendo decorrente de conflitos e rupturas conjugais mal elabo- 
radas, onde os filhos acabam sendo utilizados como objetos de vingança.

A AP, como qualquer abuso, possui severas consequências, que podem ser perpetuar pelas gerações, tornando-se um padrão de comportamento. $\mathrm{O}$ fenômeno tem, portanto, uma abrangência muito maior do que parece à primeira vista; constatação que levou à promulgação da Lei 12.318/2010.

A norma veio atribuir efeitos jurídicos à conduta, conceituando-a, exemplificando sua prática, delimitando a forma como ela é trazida em juízo e propondo diversas medidas para inibir ou cessar a alienação, ressaltando-se que a proposta da Lei não é punir os alienantes, mas preservar os filhos alienados, afastando-os de situações que possam prejudicar o seu desenvolvimento físico e psíquico.

Aquele que aliena, pode atuar de forma muito criativa e sutil, sendo difícil vislumbrar se, de fato, os filhos estão sendo vítimas da AP. Desta forma, assinalou-se, em diversos pontos do artigo, a importância da atuação psicojurídica na identificação e superação da SAP, principalmente nos casos em que são relatados possíveis abusos físicos ou emocionais. Os profissionais da área de família precisam analisar cada caso na sua subjetividade, e com sensibilidade, para muito além dos fatos narrados no papel.

Anseia-se com o dia em que os filhos poderão amar, sem culpa, pai e mãe.

Abstract: This article is the result of the brief analysis of the legal and psychological aspects of Parental Alienation Syndrome: familiar phenomenon in which disqualification of parents campaigns are carried out before the children targeting a distance between them. The issue gained prominence after the enactment of Law 12.318, of August 26, 2010, which regulated the practice of parental alienation and outlined the consequences / sanctions that have no punitive objective, but educational and protective.The theme is relevant considering 
the effects of parental alienation in the lives of all involved, especially in the alienated children. Sees the need for a multidisciplinary approach in cases where parental alienation is identified, so that the measures provided for in law are applied properly and will safeguard the right to family life of the children.

Keywords: Parental alienation. Parental alienation syndrome. Law 12,318 / 2010. Family law. Psychology

\section{REFERÊNCIAS}

BARRETO, Lucas Hayne Dantas. Considerações sobre a guarda compartilhada. 2003. Disponível em: <http://jus.com.br/artigos/4352/consideracoessobre-a-guarda-compartilhada〉. Acesso em: 27 ago. 2014.

BRAGA, Maria da Graça Reis; AMAZONAS, Maria Cristina Lopes de Almeida. Família: maternidade e procriação assistida. Psicologia em Estudo. Maringá, v. 10, n. 1, p. 11-18, jan./abr. 2005.

BRASIL. Constituição da República Federativa do Brasil de 1988.

Disponível em: <http://www.planalto.gov.br/ccivil_03/constituicao/ ConstituicaoCompilado.htm>. Acesso em: 27 ago. 2014.

BRASIL. Lei 10.046, de 10 de janeiro de 2002. Institui o Código Civil. Disponível em: <http://www.planalto.gov.br/ccivil_03/leis/2002/ L10406compilada.htm>. Acesso em: 27 ago. 2014.

BRASIL. Lei 12.318, de 26 de agosto de 2010. Dispõe sobre a alienação parental e altera o art. 236 da Lei no 8.069, de 13 de julho de 1990. Disponível em: <http://www.planalto.gov.br/ccivil_03/_Ato20072010/2010/Lei/L12318.htm>. Acesso em: 27 ago. 2014.

BRAZIL, Glicia Barbosa de Mattos. A reconstrução dos vínculos afetivos pelo Judiciário. Revista Brasileira de Direito das Famílias e Sucessões. Vol. 13, dez./jan. 2010.

CAHALI, Yussef Said. Divórcio e separação. 9 ed. rev. e atual. São Paulo: Editora Revista dos Tribunais, 2000.

CANO, Débora Staub; GABARRA, Leticia Macedo; MORÉ, Carmen Ocampo; et. al. As transições familiares do divórcio ao recasamento no 
contexto brasileiro. Psicologia: Reflexão e Crítica. 22(2), 214-222, 2008. Disponível em: 〈http://www.scielo.br/pdf/prc/v22n2/a07v22n2.pdf〉. Acesso em: 27 ago. 2014.

CANTORA SANDRA. Uni duni te. Disponível em: <http://letras.mus.br/ cantora-sandra/1640406/>. Acesso em: 27 ago. 2014.

CENTA, Maria de Lourdes; ELSEN, Ingrid. Reflexões sobre a evolução histórica da família. Família, Saúde e Desenvolvimento. América do Norte, 1, abr. 2006. Disponível em: <http://ojs.c3sl.ufpr.br/ojs2/index.php/ refased/article/view/4878/3728>. Acesso em: 27 ago. 2014.

CIRINO, Oscar. Psicanálise e psiquiatria com crianças: desenvolvimento ou estrutura. Belo Horizonte: Autêntica, 2001.

COMEL, Denise Damo. Poder Familiar: titularidade. Inconstitucionalidade da primeira parte do caput do art. 1.631 do Código Civil. Jus Navigandi. Teresina, ano 9, n. 363, 5 jul. 2004. Disponível em: <http://jus.com.br/ revista/texto/5414>. Acesso em: 27 ago. 2014.

DARNALL, Douglas. Consequências da Síndrome de Alienação Parental: sobre as crianças e sobre o genitor alienado. In: SILVA, Denise Maria Perissini da. Mediação e Guarda Compartilhada: conquistas para a família. Curitiba: Editora Juruá, 2011. p. 213.

DIAS, Maria Berenice. Incesto e alienação parental: realidades que a justiça insiste em não ver. $2^{a}$ ed. rev., atual e ampl. São Paulo: Editora Revista dos Tribunais, 2010.

Editora Revista dos Tribunais, 2010.

DILL, Michele Amaral; CALDERAN, Thanabi Bellenzier. Poder Familiar: mudança de conceito. In: Âmbito Jurídico. Rio Grande, XIII, n. 83, dez 2010. Disponível em: <http://www.ambito-juridico.com.br/site/index. php?n_link=revista_artigos_leitura\&artigo_id=8722>. Acesso em: 27 ago. 2014.

FONSECA, Priscila Maria Pereira Corrêa da. Síndrome de alienação parental. Pediatria (São Paulo). 2006; 28(3) 162-8. Disponível em: <http:// pediatriasaopaulo.usp.br/upload/pdf/1174.pdf>. Acesso em: 27 ago. 2014.

FREYRE, Gilberto. Casa-grande $\mathcal{E}$ senzala: formação da família brasileira sob o regime da economia patriarcal. 48 ed. rev. São Paulo: Global, 2003. 
GARCIA, Célio. Psicologia Jurídica: operadores do simbólico. Belo Horizonte: Editora Del Rey, 2004.

GARDNER, Richard. Future predictions on the fate of pas children: what hath alienators wrought? In: RIBEIRO, Raquel Pacheco Ribeiro de. Sindrome de alienação parental e o narcisismo. 2009. Disponível em: <http:// www.psicologiananet.com.br/psicologia-forense-sindrome-da-alienacaoparental-pesquisa-cientifica/1908/>. Acesso em: 27 ago. 2014.

\section{. O DSM-IV tem equivalente para o diagnóstico de}

Síndrome de Alienação Parental (SAP)? 2002. Disponível em: <https:// sites.google.com/site/alienacaoparental/textos-sobre-sap-1/o-dsm-iv-temequivalente>. Acesso em: 27 ago. 2014.

GOETZ, Everley; VIEIRA, Mauro. Pai real, pai ideal: o papel paterno no desenvolvimento infantil. $1^{a} \mathrm{ed}$. (ano 2009), $1^{\text {a }}$ reimp. Curitiba: Juruá, 2010.

GOUDARD, Bénédicte. A Síndrome da Alienação Parental. Dissertação apresentada à Universidade Claude Bernard-Lyon e defendida em 22 de outubro de 2008 para obtenção de título de Doutor em Medicina. Disponível em: <http://www.sos-papai.org/documentos/0.\%20 Doutorado\%20em\%20Medicina\%20-\%20A\%20SNDROME\%20DE\%20 ALIENAO\%20PARENTAL.pdf>. Acesso em: 27 ago. 2014.

LAGRASTA, Caetano. Parentes: Guardar ou Alienar - a Síndrome da Alienação Parental. Revista Brasileira de Direito das Famílias e Sucessões. Dez-Jan 2012, Ano XIII, n. 25.

MATOS, Eliete Teixeira Belfort. Família - uma rede em construção. In. Direito à convivência familiar e comunitária. São Paulo: Secretaria de Assistência e Desenvolvimento Social, 1999.

MUSSELI, Liziane Borges. A limitação do Poder Familiar no uso de medidas corretivas em face de crianças e adolescentes. JurisWay. 2011. Disponível em: 〈http://www.jurisway.org.br/v2/dhall.asp?id_dh=6229>. Acesso em: 27 ago. 2014.

NOGUEIRA, Mariana Brasil. A Família: conceito e evolução histórica e sua importância. 2012. Disponível em: <http://www.pesquisedireito.com/ artigos/civil/a-familia-conc-evol>. Acesso em: 27 ago. 2014.

NORONHA, Maressa Maelly Soares; PARRON, Stênio Ferreira. A evolução do conceito de família. Núcleo de Pesquisa da Finan. vol. 03, nº 03, 
2012. Disponível em: <http://www.finan.com.br/pitagoras/downloads/ numero3/a-evolucao-do-conceito.pdf $>$. Acesso em: 27 ago. 2014.

NUNEZ, Carla Alonso Barreiro. Guarda compartilhada: um caminho para inibir a alienação parental. Instituto Brasileiro de Direito de Família IBDFAM. 2013. Disponível em: <https://www.ibdfam.org.br/artigos/ autor/Carla\%20Alonso\%20Barreiro\%20N\%C3\%BA\%C3\%B1ez>. Acesso em: 27 ago. 2014.

OLIVEIRA, Elias Barbosa de; BITTENCOURT, Leilane Porto; CARMO, Aila Coelho do. A importância da família na prevenção do uso de drogas entre crianças e adolescentes: papel materno. SMAD: Revista Eletrônica Saúde Mental Álcool e Drogas. Vol. 4, n. 2, artigo 2, 2008. Disponível em: <http:// pepsic.bvsalud.org/pdf/smad/v4n2/v4n2a03.pdf>. Acesso em: 27 ago. 2014.

PAULO, Beatrice Marinho Paulo. Alienação Parental: identificação, tratamento e prevenção. Revista Brasileira de Direito das Famílias e Sucessões. Porto Alegre; Belo Horizonte. Ano XII, no 19, dez-jan 2011. Disponível em: <http://www.rkladvocacia.com/arquivos/artigos/art_srt_ arquivo20130422220535.pdf>. Acesso em: 27 ago. 2014.

REIS, Erika Figueiredo. Varas de Família: Um encontro entre Psicologia e Direito. Curitiba: Editora Juruá, 2009.

ROSA, Felipe Niemezewski da. A Sindrome de Alienação Parental nos casos de separações judiciais no direito civil brasileiro. 2008. Disponível em: <http:// www3.pucrs.br/pucrs/files/uni/poa/direito/graduacao/tcc/tcc2/ trabalhos2008_1/felipe_niemezewski.pdf>. Acesso em: 27 ago. 2014.

SCHENKER, Miriam; MINAYO, Maria Cecília de Souza. A importância da família no tratamento do uso abusivo de drogas: uma revisão da literatura. Cad. Súde Pública do Rio de Janeiro. 20(3): 649-659, mai-jun, 2004. Disponível em: <http://www.scielo.br/pdf/csp/v20n3/02.pdf $>$. Acesso em: 27 ago. 2014.

SILVA, Denise Maria Perissini da. Mediação e Guarda Compartilhada: conquistas para a família. Curitiba: Editora Juruá, 2011.

TOLOI, Maria Dolores Cunha. Sob fogo cruzado: conflitos conjugais na perspectiva de crianças e adolescentes. São Paulo: Ágora, 2010.

VELLY, Maria Frota. A sindrome de alienação parental: uma visão jurídica e psicológica. 2010. Disponível em: <http://www.vnaa.adv.br/artigos/ ibdfam.pdf>. Acesso em: 27 ago. 2014. 
VERSIANI, Tátilla Gomes; et. al. A Síndrome da Alienação Parental na reforma do Judiciário. In: Reforma do Judiciário, do Curso de Direito da Universidade Estadual de Montes Claros-UNIMONTES. 2009. Disponível em: 〈http://www.alienacaoparental.com.br/textos-sobre-sap>. Acesso em: 27 ago. 2014.

VIEIRA, Patrício Jorge Lobo. O dano moral na Alienação Parental. Revista Brasileira de Direito das Famílias e Sucessões. Dez-Jan 2013, Ano XIV, n. ${ }^{\circ} 31$.

VIEIRA SEGUNDO, Luiz Carlos Furquim. Sindrome da Alienação Parental: o Bullying nas relações familiares. 2009. Disponível em: <http:// www.mp.ce.gov.br/orgaos/CAOCC/dirFamila/artigos/02.sindrome. da.alienacao.parental.pdf>. Acesso em: 27 ago. 2014. 